\title{
Improved Feature Extraction of Hand Movement EEG Signals based on Independent Component Analysis and Spatial Filter
}

\author{
응웬탄하 · 박승민 · 고광은 · 심귀보 ${ }^{\dagger}$ \\ Thanh Ha Nguyen, Seung-Min Park, Kwang-Eun Ko, and Kwee-Bo Sim ${ }^{\dagger}$ \\ 중앙대학교 전자전기공학부
}

\begin{abstract}
In brain computer interface (BCI) system, the most important part is classification of human thoughts in order to translate into commands. The more accuracy result in classification the system gets, the more effective BCI system is. To increase the quality of BCI system, we proposed to reduce noise and artifact from the recording data to analyzing data. We used auditory stimuli instead of visual ones to eliminate the eye movement, unwanted visual activation, gaze control. We applied independent component analysis (ICA) algorithm to purify the sources which constructed the raw signals. One of the most famous spatial filter in BCI context is common spatial patterns (CSP), which maximize one class while minimize the other by using covariance matrix. ICA and CSP also do the filter job, as a raw filter and refinement, which increase the classification result of linear discriminant analysis (LDA).
\end{abstract}

Key words : Brain-Computer Interface (BCI), Electroencephalogram (EEG), Common Spatial Patterns (CSP), Independent Component Analysis, Auditory Stimuli

\section{Introduction}

Brain-computer interface (BCI) system, translate or decode the human brain signal to control outer device without movement. Human brain signals which are mostly used is electroencelophagram (EEG) signal. Recording based on the users attention for visual/audio stimuli, and coding user's attention to commands to control the system. Most of all cue for attention are based on visual stimuli, such as: Visual epoched potential (VEP), steady state visual epoched potential (SSVEP).. as mentioned in[1]. On the other hand, EEG based on visual cue contaminated artifacts and noise not only insisted by muscle or EEG properties, but also caused by unwanted activated from eye gaze of users. In this study, we applied auditory stimuli in order to replace visual studio in designing BCI systems[2]. Auditory cue for attention was supposed that could reduce the noise caused by eye movement or unwanted respond by eye gaze. In auditory experiment, subjects were instructed to closed eye and relaxed so that they

접수일자: 2012년 4월 20일

심사(수정)일자: 2012년 4월 20일

게재확정일자 : 2012년 7월 21일

+ 교신 저자

본 논문은 본 학회 2012년도 춘계학술대회에서 선정된

우수논문입니다.

본 논문은 2011년도 정부(교육과학기술부)의 재원으로 한국연구재단의 중견연구자지원사업 도약연구(전략)과제 로 수행된 연구입니다(No.2011-0029861). 연구비지원에 감사드립니다. could concentrate on hearing the cue and not be attacked by unwanted visual stimuli when recording signals. BCI systems are famous of applying for patient who lost limb in accident or disease of brain function, ... So in almost experiments of BCI systems cue for task of limbs movement imagination or execution. Such as in [3-5], all EEG data recorded were hand movement, foot movement and also tongue imagination movement. In neuro-physiological point of view, the intention is influenced by the rhythmic activity in specific locations over the sensori-motor cortex. BCI systems's work is detection the difference between each movements, selected them as features and coding them to command to communicate with devices. But EEG signals are non-invasive technique so that noise also recorded with brain signal in EEG data.

In BCI systems, quality and quantity of the signals were influenced by the low signal-to-noise ratio (SNR) and the non-stationaries sources of the brain signals. subjects and time scales. These properties make the BCI systems need to be purified noise by robust nonstationary over brain signals [6]. In our previous work, we applied independent components analysis (ICA) to estimate the sources that caused EEG signals, based on those components. We assumed that brain signals were the sources that got bigger percentage of accounting variance value. From ICA technique, we could reduce the dimension of the signal from so many components contained noise. We reduced noise component aim to purify the signals. With a small number (around 20-25 $\%$ components were kept and $75-80 \%$ of components are eliminated) of components, a new space were 
reconstructed. Even though, [6] ICA could filter the noise sources caused by outer brain but there were still artifacts that occurred inside brain which caused by non-stationary character.

In order to solve the inner noise sources[7], common spatial pattern (CSP) is a powerful technique. CSP is the famous algorithm, which maximize one condition while minimize the other[4][5], for a binary choice separation. CSP technique in[2-5] shown the effectiveness of CSP in BCI context. In this paper, we used ICA and CSP to filter the signal with purposed to increase the classification results. As previous work, the ICA technique could upgrade the results. We supposed CSP also could improve the classification result of classifiers. We applied two different algorithms to classify, they are linear discriminant analysis (LDA) and support vector machine (SVM) to evaluate the advance of CSP and ICA in extracting features.

\section{Related work}

\subsection{Independent Component Analysis (ICA)}

If $x(t)$ is original $M \times N$ EEG signal and statistically $M \times N$ independent component $s(t)$ is unknown, an instantaneous linear mixture matrix $A$ can be calculated by equation (1). The element $a_{i j}$ of $A$ is weight of mixing components[2].

$$
x(t)=A s(t)
$$

$A$ is always squared as $[M \times M]$, because the size of sources is equal to the size of observed signals. So we can express the inverse matrix $A$ to decoding matrix $W$ as shown in equation (2).

$$
s(t)=A^{-1} x(t)=W x(t)
$$

From these sources, we could analyze and determine which sources we kept to more analyze and which sources we reduced as noise part. ICA also applied as blind source separation (BSS) in many fields of preprocessing signals.

\subsection{Common Spatial Patterns (CSP)}

CSPs has been widely used in BCI systems and highly successful in calculating spatial filter for detecting event-related potentials, especially for an decrease or increase of band-power values, namely event-related desynchronized and event-related synchronized (ERD/ERS) respectively[7]. Since variance of band-pass filtered signals is equal to band-power, CSP algorithm is suited to classify mental task that are characterized by ERD/ERS, which usually used analysis in motor activity for both actual and imagination. CSP is fit to an- alyze the differences in band power between two conditions. The aim of this algorithm was solved by maximizing the Rayleigh quotient for each condition. As in[7], we assume that $C_{1}$ and $C_{2}$ are the average covariance matrices from class 1 and class $2 \mathrm{re}^{-}$ spectively, equation (3) illustrates for condition $i=1$ and 2:

$$
R_{w}=\frac{w^{T} C_{i} w}{w^{T}\left(C_{1}+C_{2}\right) w}
$$

In order to solve this maximization of the Rayleigh quotient as maximize one class with:

$$
w^{T}\left(C_{1}+C_{2}\right) w-b=0
$$

Where $b$ is an arbitrary constant (the norm of $\mathrm{w}$ can be chosen so that equation (4) holds) and solved by using Lagrange multipliers is:

$$
L(\lambda, w)=w^{T} C_{1} w-\lambda\left(w^{T}\left(C_{1}+C_{2}\right) w-b\right)
$$

The filters $\mathrm{w}$ can be defined by the derivative of $\mathrm{L}$ with respect to $\mathrm{w}$ equal 0 :

$$
\begin{aligned}
\frac{\partial L}{\partial w} & =2 w^{T} C_{1}-2 \lambda w^{T}\left(C_{1}+C_{2}\right)=0 \\
& \Leftrightarrow C_{1} w=\lambda\left(C_{1}+C_{2}\right) w \\
& \Leftrightarrow\left(C_{1}+C_{2}\right)^{-1} C_{1} w=\lambda w
\end{aligned}
$$

We can solve this problem by using eigenvalue and eigenvector. With largest eigenvalue corresponds to the spatial filters that maximizes the variance of class 1 $\left(C_{1}\right)$ while minimize the common variance $\left(C_{1}+C_{2}\right)$. The same progress for condition 2 and get the filter fitted to equation (3) and (4). It is simple generalization eigenvector with smallest eigenvalue. In this case the largest eigenvalue of this condition is the smallest eigenvalue of another condition.

\section{Experimental Method}

\subsection{Data acquisition}

Figure 1. shows our auditory paradigm, there are three kinds of sounds, including: 1) right hand movement instruction (signal \# $=20,500 \mathrm{~Hz}$ ), 2) left hand movement instruction ( signal $\#=10,2000 \mathrm{~Hz}$ ), and 3) ignored noise sound. All subjects had two sessions with different conditions: closed-eye and open-eye. We recorded EEG signals by using 64 channels EEG (Synamp2, NeuroScan Corp.) and the sampling rate equals $1000 \mathrm{~Hz}$. Since this study concentrated executive 
movement so we recorded signals with 25 channels. In the term of neuro-physiologic, limb movements are controlled by the motor cortex area over the head. For a specific analysis of hand movement[8], we chose 25 channels as fig. 1b), where cover the motor cortex and especially channels $\mathrm{C} 3$ and C4. It is said that these 2 channels were analyzed for limb movements.

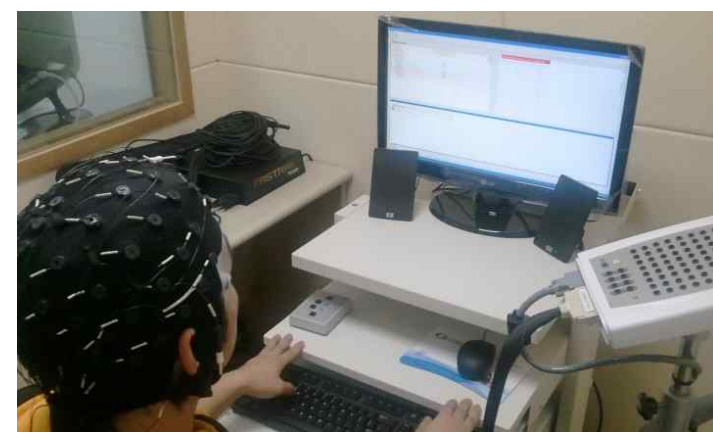

a) 25 channels location

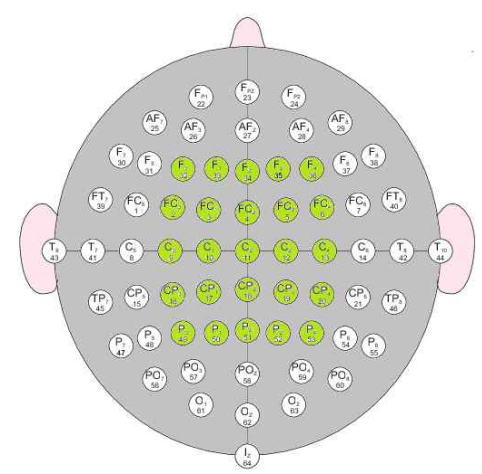

b) channel locations and setup

Fig. 1. EEG acquisition: a) subject and Stim2 and b) channel selection

Subjects were instructed to sit down and relaxed, just concentrated to hear the sound and respond as instructed above. Data analyzing from 2 subjects, who have averaging of age is 26.5 year-old and both are healthy subjects (one is left handed). All subjects are our laboratory graduate student, who the first time recorded EEG signals and BCI system.

\subsection{Preprocessing}

As mentioned before, the physiological shown that limb movement was analyzed in $\mu(8-13 \mathrm{~Hz})$ and $\beta$ (12-25 Hz) rhythms[9]. In our specific executive hand movement we more concentrated on $\mu$ rhythm cover the $\alpha$ band $(8-12 \mathrm{~Hz}$ ) for motor rhythms and hand movement. In this study, we did the band pass filter from 8 to $13 \mathrm{~Hz}$ for reducing the noise of muscle and subjects movements. The data after denoising were continuously studied for eliminating the outer noise by using ICA algorithm. Signal, after recording, was whitening by band pass filter in the $\mu$ rhythms follow ${ }^{-}$ ing the neurological information. Then it was consider as input for eeglab application to approximate the independent sources. We extracted epochs of 2 conditions and then removing the bad sources separately in 2 conditions. as in figure 2 .

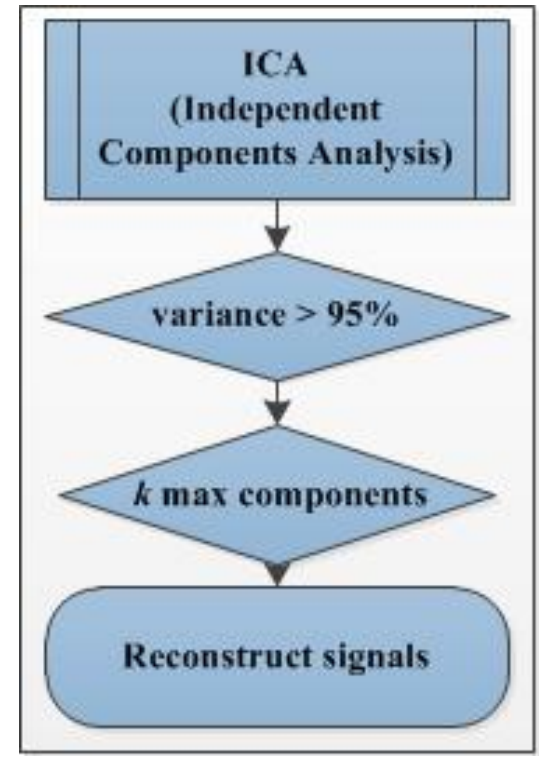

Fig. 2. Independent Component Analysis method for denoising signal

Based on the accounted variance, we chose the maximum covariance accumulation up to $95 \%$. In this study, the number of components were chose to be kept was around $20-30 \%$ of total 25 components. So we reduced the bad components and just kept small number of components to reconstruct and analyze.

\subsection{Feature extraction and Classification:}

Data after applied preprocessing step, we analyzed for CSP to archive spatial filter for 2 class of hand movement. CSP with target to get the maximum of one condition and the same time get the minimum for the rest class. By using eeglab application, we extracted epochs of each condition. Epochs in this experiment were extracted more concentrate about the real movement when subject did and analyzing based on the different of the subject around 300ms after stimuli. In the previous work, we also analyzed this part of EEG signals. In this study we still keep the epoch time same with last time analyzed and based on P300 technique. Covariance matrices were calculated for 2 conditions each condition gather of 35 trials. We chose 2 features both are maximum of each condition. In fact that, one is maximum of this condition, also is minimum of the other condition. Common spatial pattern

From these features, we reconstructed again the signals and it was the input of the classification. In this 
study, we used support vector machine (SVM) for classifier. In the previous work we used linear discriminant analysis (LDA). we could compare previous work and this study to find out the advantage of combination between two kinds of filters. The results were calculated by 5 fold-cross validation to evaluate the advance of the method and classifiers.

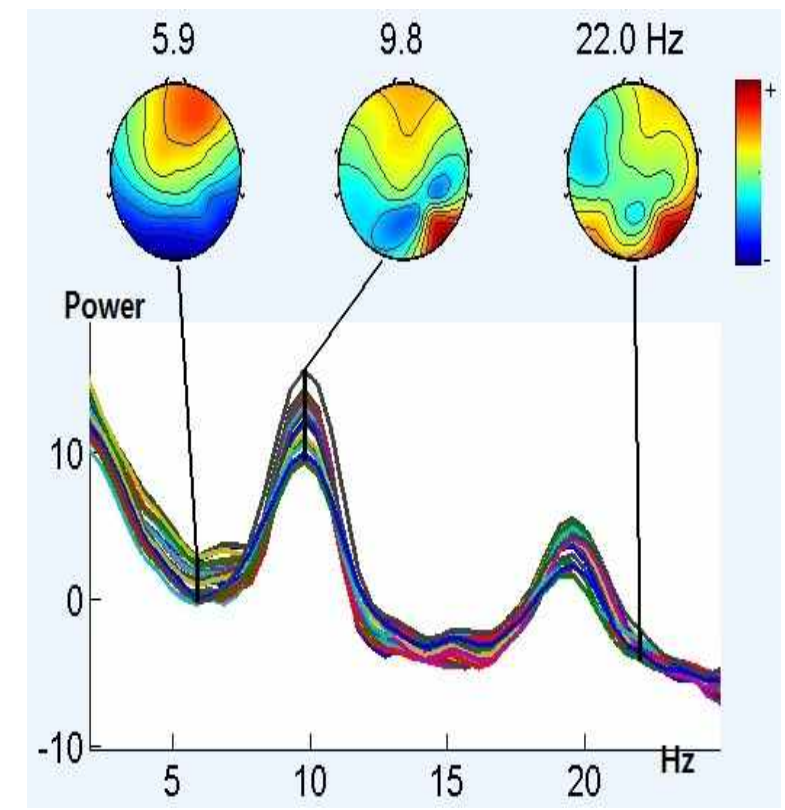

Fig. 3. Frequency domain of raw signals and three specific frequency analyzing topography

\section{Results}

It is also announced that the hand movement appeared in mu rhythms specific band $8-13 \mathrm{~Hz}$ or foot movement appeared in beta rebound[9][10] in neuro-physiological knowledge. In the figure 3, frequency domain of original signals shown the fact that the real hand movement appeared peak and high power in $\mu$ rhythm, in this case was around $8-13 \mathrm{~Hz}$ and got peak at $10 \mathrm{~Hz}$. Figure also shown the same fact announced in the neurophysiological point of view[10], and three picture of head distribution of topography around three specific frequency: $6 \mathrm{~Hz}, 10 \mathrm{~Hz}$, and $22 \mathrm{~Hz}$. From three topography we could estimate the high or low amplitude of EEG signals over the brain with specific frequencies.

After using ICA algorithms for 25 channels, we estimated 25 components for each dataset. In each dataset we got different estimate sources so that the number of components to be kept also was different. Each data had various number of components gathered to get over $95 \%$ but it was still a very small number compared to total number in this case was 25 components. In figure 4 , there are 5 red circles of 5 first components shown the components were chosen in that data based on the variance accounted.

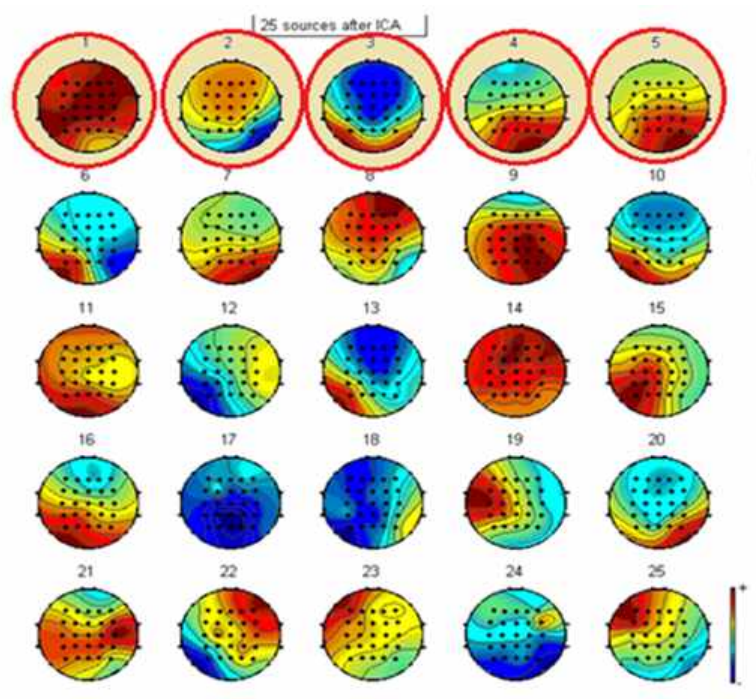

25 ICA sources from original signal

Fig. 4. 25 components from ICA algorithms results distribute over averaging of 25 channels

We applied to analyzed: $50 \%$ data for training and $50 \%$ data for testing. We used 5 cross $^{-}$validation for random running test to have results in the table 1 . We could easily find out that SVM technique always got the better results for all dataset. In this study, for a specific test analysis, we gathered detail results in which some were equal for two methods. Compared to the previous work which was only applied ICA for feature extraction. From previous work[11] the max result only get $58.6 \%$ as shown in the last row of table 1 . We could easily to find out that combination with CSP the result of classification increase 27.97\% (LDA) and $32.25 \%$ (SVM) for subject 1 session 1 same dataset. The different between two classifiers was not much around $5 \%$ but the difference between ICA and ICA + CSP over 20\% accuracy of classification methods. In this study, we applied for 4 data sets of two subjects. Previous work we only analyzed from 2 data sets of two subjects.

Table 1. Classification accuracy of LDA and CSP methods of 2 subjects (S1 and S2)

\begin{tabular}{|c|c|c|c|c|}
\hline \multirow{2}{*}{$\begin{array}{c}\text { Accuracy } \\
\text { Classificati } \\
\text { on (\%) }\end{array}$} & \multicolumn{2}{|c|}{ Subject 1 } & \multicolumn{2}{c|}{ Subject 2 } \\
\cline { 2 - 5 } & Session 1 & Session 2 & Session 1 & Session 2 \\
\hline LDA & $86.57 \%$ & $71.8 \%$ & $74.19 \%$ & $87.44 \%$ \\
\hline SVM & $90.85 \%$ & $74.2 \%$ & $77.64 \%$ & $87.85 \%$ \\
\hline ICA-LDA & $58.6 \%$ & - & $54 \%$ & - \\
\hline
\end{tabular}




\section{Discussions}

Auditory stimuli also could get good result for real hand movements as visual stimuli could. From the EEG data, we could find out that the auditory stimuli could get a clearer EEG signal than visual stimuli EEG signals. The number of the interesting components was $20-25 \%$ of all 25 components but still kept the interesting information in EEG signals. That is the reason why could increase the result of classifier in the previous work. Even though the subjects did not have training data set to train the brain state in order to get some brain states the classification result was rather good. In this study, we proposed to combined ICA as a raw filter and CSP as a second filter for reducing noise, artifacts, and also maximize one condition while minimize the other in EEG signals. The classification results of 2 classifiers shown the improvement of the classification result. Last study [11], only ICA could increase around $10 \%$ for the same data set compared to raw signals. In this study, the results increase over $20 \%$ compared to only using ICA for feature extraction.

But the different number of kept components from each subjects and same subject but different session still different based on subjects and sessions. This problem was created by the invariant character of EEG signals transferring from subject-to-subject and session-to-session. In the future, we will analyze this experiment for imagery movement and for disable subjects. In order to create a perfect BCI system control outer devices for all healthy and prosthetic subjects. So that a dynamic system which could have recognition brain state well and also solve the problem of transfer subjects and session.

\section{참 고 문 헌}

[1] D. Zhu, J. Bieger, G G Molina and R M Aarts, "A Survey of Stimulation Methods Used in SSVEP-Based BCIs," Computational Intelligence and Neuroscience, vol. 2010, pp. 1 - 12. 2010.

[2] J. Guo, S. Gao, B. Hong, "An auditory brain-computer interface using active mental response," IEEE Transaction Neural System Rehabilitation Engineering. vol. 18, issue 3, pp. 230-235, Jun 2010.

[3] C. Guger, H. Ramoser, "Real-time EEG analysis with subject-specific spatial patterns for a brain-computer interface (BCI)," IEEE Transactions on Rehabilitation Engineering, vol. 8, no. 4, pp. 447-456. Dec 2000.

[4] W. Wojcikiewicz , C. Vidaurre, M. Kawanabe, "Stationary Common Spatial Patterns: Towards robust classification of non-stationary EEG signals," IEEE International Conference Acoustics, Speech and Signal Processing (ICASSP), pp. 577-580. 22-27 May 2011.

[5] P. von Bünau, F.C. Meinecke, F. Király, K.-R. Müller,: "Finding stationary subspaces in multivariate time series," Physical Review Letters, vol. 103, p. 214101, 2009.

[6] M. Ungureanu, C. Bigan, R. Strungaru, V. Lazarescu.,: "Independent Component Analysis Applied in Biomedical Signal Processing", Measurement Science Review, vol. 4 sec. 2, pp. 1 8, 2004.

[7] S. Choi and A. Cichocki.: "Algebraic Differential Decorrelatation for Nonstationary Source Separation," Electronics Letters, vol. 37, no. 23, pp. 1414-1415, 8 November 2001.

[8] G. R. Müller-Putz, D. Zimmermann, B. Graimann, K. Nestinger, G. Korisek, and G. Pfurtscheller, "Event-related beta EEG-changes during passive and attempted foot movements in paraplegic patients." Brain research, vol. 1137, no. 1, pp. 84-91, March 2007.

[9] B. A. S. Hasan and J. Q. Gan, "Conditional random fields as classifiers for three-class motor-imagery brain-computer interfaces.,"Journal of neural engineering, vol. 8, no. 2, pp. 025013, Apr. 2011.

[10] Budzynski, Evans \& Abarbanel: "Introduction of Quantitative EGG and Neurofeedback Second Edition Advanced Theory and Applications" Academic Press, chapter 6, pp. 143-166, 2008.

[11] H. T. Nguyen, S. M. Park, K. E. Ko and K. B. Sim. "Independent Component Analysis-based Robust Feature Extraction of Two Class-Hand Movements from Auditory Stimuli." Proceedings of KIIS Spring Conference 2012, vol. 22, no. 1, pp. 7-8, Apr. 2012

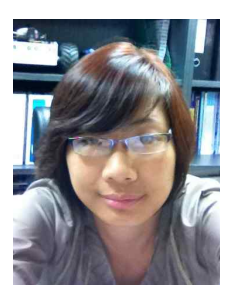

응웬탄하(Thanh Ha Nguyen)

2010년 : Electrics Engineering, Hanoi University of Science Technology, Hanoi, Vietnam

2011년 현재 : Electronics and Electric Engineering, Chung ang University, Seoul, Republic of Korea.

관심분야 : Brain-Computer Interface, Machine Learning, Neuro-Robotics, Embedded System 등

Phone : 02-820-5319

E-mail : nguyenha@cau.ac.kr 


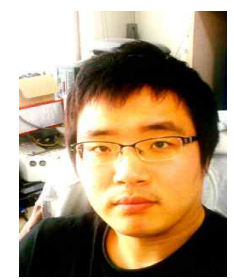

박승민(Seung-Min Park)

2010년 : 중앙대학교 전자전기공학부 공학사

2010년 현재 : 중앙대학교 대학원

전자전기공학부

석박사통합과정
관심분야 : Brain-Computer Interface, Intention Recognition Soft Computing 등

Phone : 02-820-5319

E-mail : sminpark@cau.ac.kr

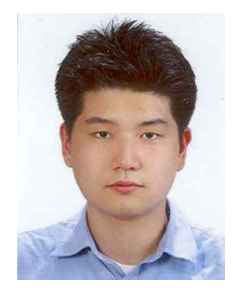

\section{고광은(Kwang-Eun Ko)}

2007년 : 중앙대학교 전자전기공학부 공학사

2007년 현재 : 중앙대학교 대학원

전자전기공학부

석박사통합과정

관심분야 : Multi-Agent Robotic Systems (MARS),

Machine Learning, Context Awareness,

Emotion Recognition Systems 등

Phone : 02-820-5319

E-mail : kkeun@cau.ac.kr

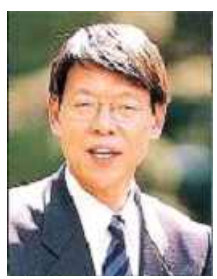

심귀보(Kwee-Bo Sim)

1990년 : The University of Tokyo 전자공학과 공학박사

1991년 현재 : 중앙대학교 전자전기공 학부 교수

2006년 2007년 : 한국지능시스템학회 회장

관심분야 : 인공생명, 뇌-컴퓨터 인터페이스, 의도인식, 감성인 식, 유비쿼터스 지능형로봇, 지능시스템, 컴퓨테이 셔널 인텔리젼스, 지능형 홈 및 홈 네트워크, 유비쿼 터스 컴퓨팅 및 센서 네트워크, 소프트 컴퓨팅(신경 망, 퍼지, 진화연산), 다개체 및 자율분산로봇시스템, 인공면역시스템, 지능형 감시시스템 등.

Phone : 02-820-5319

E-mail : kbsim@cau.ac.kr

Homepage URL : http://alife.cau.ac.kr 